Check for updates

Cite this: RSC Adv., 2019, 9, 39082

Received 29th September 2019

Accepted 21st November 2019

DOI: $10.1039 / c 9 r a 07917 c$

rsc.li/rsc-advances

\section{New spirobisnaphthalenes from an endolichenic fungus strain CGMCC 3.15192 and their anticancer effects through the P53-P21 pathway $\dagger$}

\author{
Jingwen Li, $\stackrel{+}{a}^{a}$ Rong Ding, $\dot{t}^{b}$ Hao Gao, (D) Liangdong Guo, ${ }^{c}$ Xinsheng Yao, (D) a \\ Youwei Zhang*d and Jinshan Tang (D) *a
}

\begin{abstract}
Natural products from fungi have remained a rich resource for drug discovery. Here we report the isolation of three new spirobisnaphthalenes, namely sacrosomycin A-C (1-3), and three known analogues (4-6), from the ethyl acetate extract of a nonsporulating endolichenic fungus derived from Peltigera elisabethae var. mauritzii. The structures of these compounds were elucidated by IR, UV, MS, and NMR. Biological functions of these compounds were evaluated using cultured human cancer cell lines. Shortterm cell growth and long-term cell survival assays show that compound 5 demonstrated the strongest cancer cell growth inhibition effect. We reveal that compound 5 induced both cell cycle arrest at the G2/M phase and cell death. Using western blotting, luciferase reporter assay and quantitative PCR (qPCR), we show that compound 5 induced up-regulation of the P53-P21 pathway, supporting the cell cycle arrest and growth inhibition effect of this compound. In contrast, these compounds did not induce cell death in a normal cell line. These results demonstrate a potential anticancer effect of this rare family of spirobisnaphthalene compounds isolated from endolichenic fungi.
\end{abstract}

\section{Introduction}

Spirobisnaphthalenes, also called bisnaphthospiroketals, belong to a relatively rare family of bioactive natural products that contain a 1,8-dihydroxynaphthalene derived spiroketal unit linked to a second, oxidized naphthalene moiety. ${ }^{1-3}$ Generally, spirobisnaphthalenes are divided into three subtypes, namely, spiroxin, preussomerin and deoxypreussomerin according to the linkage type of the two naphthalene rings, with the former joined together by two oxygen bridges and one carbon-carbon bridge and the later both joined together with three or two oxygen bridges, respectively. ${ }^{4}$ Recently, a small group of the fourth subtype of spirobisnaphthalenes was also discovered with only eight compounds reported up to now. ${ }^{5-7}$

${ }^{a}$ Institute of Traditional Chinese Medicine and Natural Products, International Cooperative Laboratory of Traditional Chinese Medicine Modernization and Innovative Drug Development of Chinese Ministry of Education (MOE), College of Pharmacy, Jinan University, Guangzhou 510632, P. R. China. E-mail: gztangjinshan@126.com

${ }^{b}$ School of Pharmaceutical Science, Xiamen University, Xiamen 361005, P. R. China ${ }^{c}$ State Key Laboratory of Mycology, Institute of Microbiology, Chinese Academy of Science, Beijing 100101, P. R. China

${ }^{d}$ Department of Pharmacology, Case Comprehensive Cancer Center, Case Western Reserve University, School of Medicine, Cleveland, OH 44106, USA. E-mail: yxzl69@ case.edu

† Electronic supplementary information (ESI) available: The 1D and 2D NMR, HRESIMS, IR and CD spectra of compounds 1-3. See DOI: 10.1039/c9ra07917c

\$ Equally to this work.
Spirobisnaphthalenes have attracted much attention because of their unique structures and broad spectrum of biological activities including antibacterial, antifungal, herbicidal, cytotoxic and anti-tumor activities. ${ }^{3,7}$ The unique skeleton and broad spectrum of bioactivities of spirobisnaphthalenes demonstrate great promise for the discovery of new agents for the treatment of human diseases, especially cancer.

P53 is a transcriptional factor that regulates the expression of a cascade of genes involved in cell cycle, apoptosis, autophagy, metabolism, pluripotency, and many other cellular processes. ${ }^{\mathbf{8}}$ P53 induces apoptosis through inducing expression of the proapoptotic BCL-2 family proteins including PUMA, BAX, NOXA, etc. ${ }^{9-12}$ On the other hand, P53 induces upregulation of P21, ${ }^{13-16}$ contributing largely to the cell cycle arrest function of P53. ${ }^{17,18}$ Hence, P53 is a critical gene in suppressing tumorigenesis. ${ }^{19}$ Consistently, P53 mutation is detected in almost half of all human cancers. ${ }^{16}$ P21 is an endogenous inhibitor of the cyclindependent kinase, which inhibits cell cycle progression genes such as CDC25C, CDK1, CDK2, CCNE1, CCNB1, etc. ${ }^{20,21}$ leading to cell cycle arrest in G1 or G2/M phase. ${ }^{\mathbf{1 6 , 2 2 - 2 4}}$

As part of our ongoing efforts to search for new bioactive metabolites from rarely studied fungal species, we cultured a nonsporulating endolichenic fungus (CGMCC 3.15192) derived from Peltigera elisabethae var. mauritzii. From the ethyl acetate extract, we isolated three new spirobisnaphthalenes named sarcosomycin A-C (1-3) and three known analogues (46). Here we report the isolation, structural elucidation of sarcosomycin A-C (1-3) and biological assessment of these six 


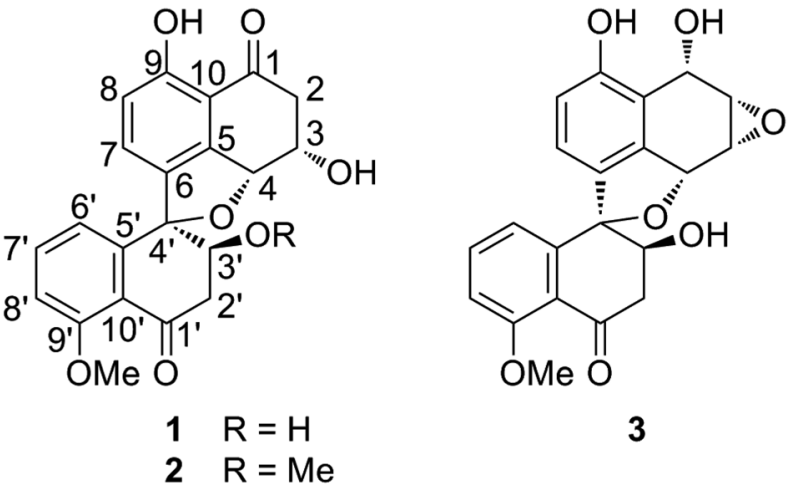

Fig. 1 Chemical structures of compounds 1-3.

compounds in the anticancer regimen. Our results show that compound $\mathbf{5}$ exhibited the strongest anticancer effect in cultured human cancer cell lines. We further reveal that this compound induced cell cycle arrest through up-regulating the P53-P21 pathway. These data demonstrate potential anticancer activity of spirobisnaphthalene compounds, laying foundation for detailed medicinal chemistry research for these compounds in the near future.

\section{Results and discussion}

\section{Chemical identification of spirobisnaphthalenes}

The fungus strain (CGMCC 3.15192) was cultured in solid state fermentation with rice at $25{ }^{\circ} \mathrm{C}$ for 47 days. The fermented material was extracted with ethyl acetate (EtOAc) and the extracts were subjected to silica gel and ODS column chromatography, which yielded five fractions (W1-W5). Preliminary screening
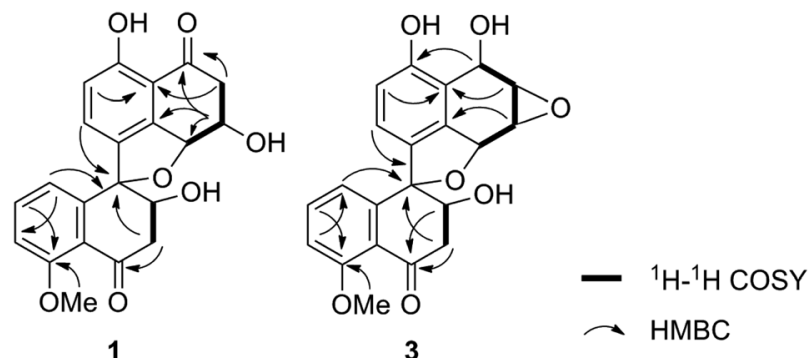

Fig. 2 Key ${ }^{1} \mathrm{H}-{ }^{1} \mathrm{H}$ COSY and $\mathrm{HMBC}$ correlations of compounds 1 and 3.

revealed that fractions $\mathrm{W} 2\left(50 \% \mathrm{MeOH}\right.$ in $\left.\mathrm{H}_{2} \mathrm{O}\right)$ and $\mathrm{W} 3(70 \%$ $\mathrm{MeOH}$ in $\mathrm{H}_{2} \mathrm{O}$ ) showed different degrees of cytotoxic activities against five cancer cell lines (HL-60, SMMC-7721, A-549, MCF-7 and SW480). Hence, fractions W2 and W3 were further subjected to silica gel, ODS, Sephadex LH 20 column chromatography and RPHPLC to yield three new spirobisnaphthalenes, named sarcosomycin A-C (1-3), along with urnucratin C (4), Plecmillin A (5), and Plecmillin C (6) (Fig. 1).

Sarcosomycin A (1) was obtained as a yellow amorphous powder. The molecular formula was established as $\mathrm{C}_{21} \mathrm{H}_{18} \mathrm{O}_{7}$ by HRESIMS $\left(\mathrm{m} / \mathrm{z} 383.1116[\mathrm{M}+\mathrm{H}]^{+}\right.$, calcd for $\left.\mathrm{C}_{21} \mathrm{H}_{19} \mathrm{O}_{7}: 383.1131\right)$, indicating $13^{\circ}$ of unsaturation. The IR absorption implied the presence of hydroxyls, $\alpha, \beta$-unsaturated ketone and aromatic ring at 3423, 1656 (broad single peak), 1594, $1474 \mathrm{~cm}^{-1}$. The ${ }^{1} \mathrm{H}$ NMR spectrum showed the presence of a 1,2,3-trisubstituted aromatic protons at $\delta_{\mathrm{H}} 6.80(1 \mathrm{H}, \mathrm{d}, 8.0 \mathrm{~Hz}), 7.16(1 \mathrm{H}, \mathrm{d}, 8.0 \mathrm{~Hz})$, and $7.15(1 \mathrm{H}, \mathrm{t}, 8.0 \mathrm{~Hz})$, a 1,2,3,4-tetrasubstituted aromatic protons at $\delta_{\mathrm{H}} 6.94(1 \mathrm{H}, \mathrm{d}, 8.4 \mathrm{~Hz})$ and $7.35(1 \mathrm{H}, \mathrm{d}, 8.0 \mathrm{~Hz})$, and a methoxy proton at $\delta_{\mathrm{H}} 3.89(3 \mathrm{H}, \mathrm{s})$. The ${ }^{13} \mathrm{C}$ NMR spectrum

Table 1 The ${ }^{1} \mathrm{H}$ and ${ }^{13} \mathrm{C}$-NMR data of $1-3\left(400 \mathrm{MHz}\right.$ for ${ }^{1} \mathrm{H}$ and $100 \mathrm{MHz}$ for ${ }^{13} \mathrm{C}$ in $\left.\mathrm{CD}_{3} \mathrm{OD}\right)$

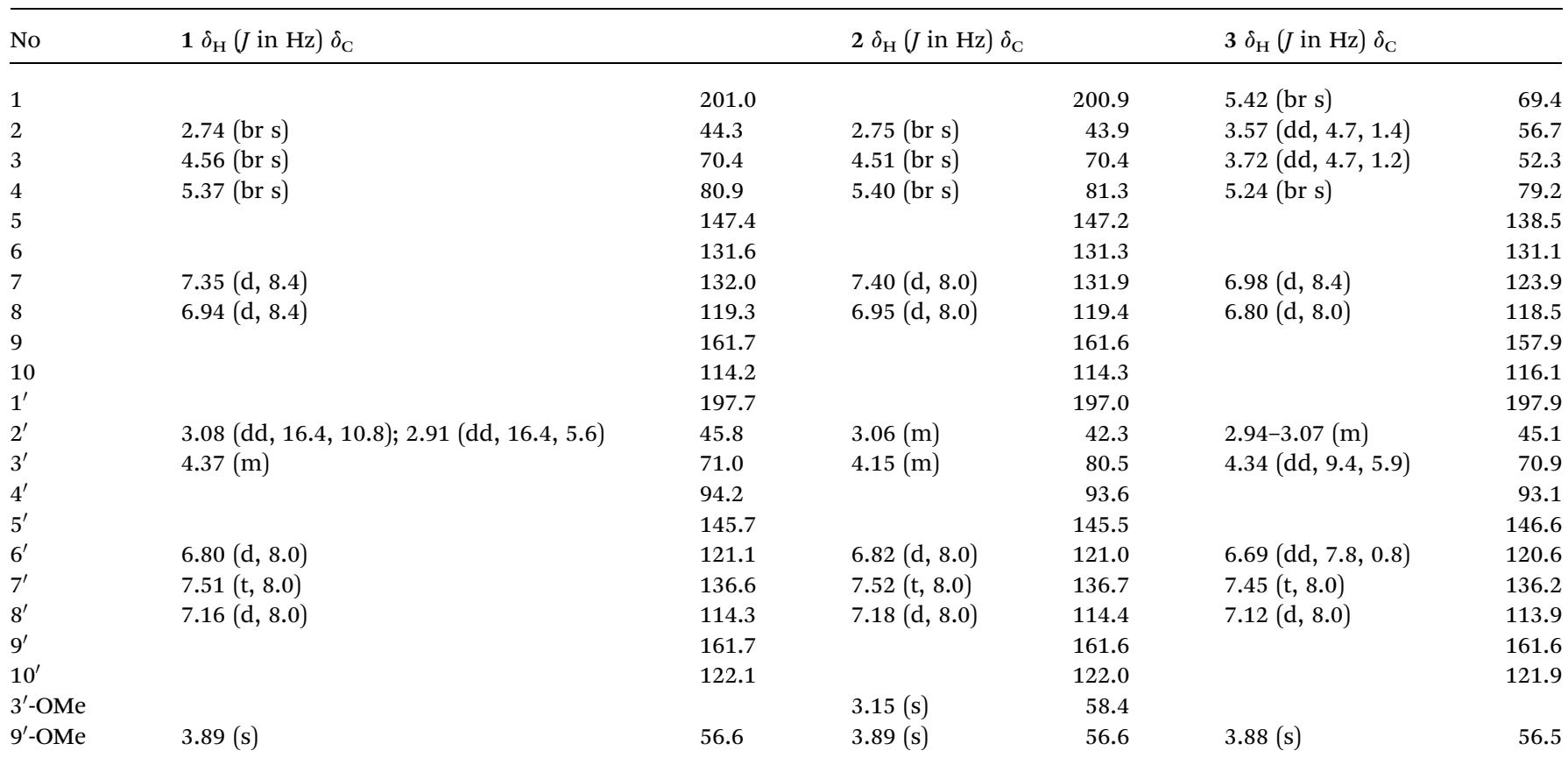



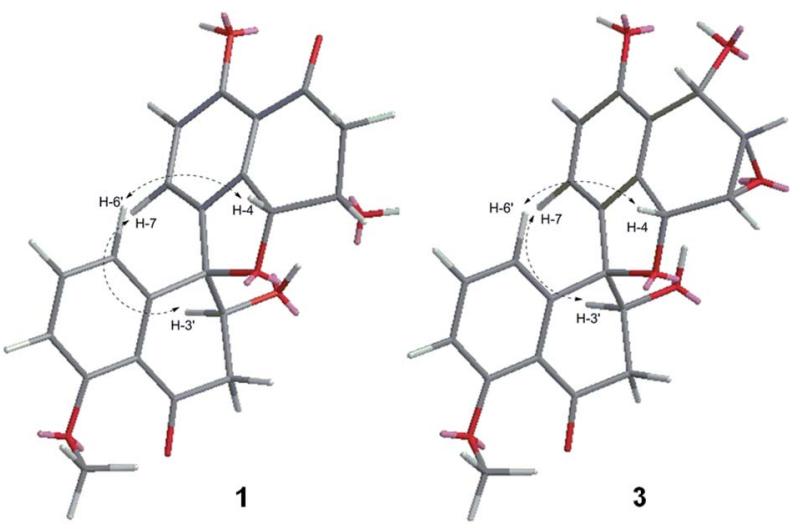

Fig. 3 Key 1D selective NOE correlations of compounds 1 and 3 .

displayed two carbonyl groups at $\delta_{\mathrm{C}} 197.7$ and 201.0, twelve aromatic carbons from $\delta_{\mathrm{C}} 114.2$ to 161.8 , four oxygenated carbons at $\delta_{\mathrm{C}} 70.4,71.0,80.9$, and 94.2, two methylene carbons at $\delta_{\mathrm{C}} 44.3$ and 45.8 , and a methoxy carbon at $\delta_{\mathrm{C}}$ 56.6. Comparison of the ${ }^{1} \mathrm{H}$ and ${ }^{13} \mathrm{C}$ NMR data of $\mathbf{1}$ with that of Plecmillin $\mathrm{C}$ indicated that they had similar spirobisnaphthalene skeleton (Table 1). ${ }^{5}$ The presence of one oxymethine carbon signal at $\delta_{\mathrm{C}}$ 71.0 and one methylene carbon signal at $\delta_{\mathrm{C}} 45.8$ instead of a pair of olefinic carbon signals in the ${ }^{13} \mathrm{C}$ NMR spectrum of 1 suggested that the olefinic bond of $\alpha, \beta$-unsaturated ketone was reduced and hydroxylated in compound 1. Analyses of ${ }^{1} \mathrm{H}-{ }^{1} \mathrm{H}$ COSY, HSQC and HMBC correlations established the planar structure of 1 (Fig. 2).

The relative configuration of 1 was determined by 1D selective NOE experiments, in which irradiation of $\mathrm{H}-4\left(\delta_{\mathrm{H}} 5.37,1 \mathrm{H}\right.$, br s) enhanced $\mathrm{H}-6^{\prime}\left(\delta_{\mathrm{H}} 6.80,1 \mathrm{H}, \mathrm{d}, 8.0 \mathrm{~Hz}\right)$, while irradiation of $\mathrm{H}-3^{\prime}\left(\delta_{\mathrm{H}} 4.37,1 \mathrm{H}, \mathrm{m}\right)$ enhanced $\mathrm{H}-7\left(\delta_{\mathrm{H}} 7.35,1 \mathrm{H}, \mathrm{d}, 8.4 \mathrm{~Hz}\right)$ (Fig. 3). Thus, the relative configurations of 1 were identified to be $3 S^{*}, 4 R^{*}, 3^{\prime} S^{*}, 4^{\prime} R^{*}$. The CD cotton effects of $\mathbf{1}$ were consistent with that of urnucratin A, indicating the absolute configuration of 1 as $3 S, 4 R, 3^{\prime} S, 4^{\prime} R$ (Fig. S9†). ${ }^{6}$

Sarcosomycin B (2) was obtained as a yellow amorphous powder. The molecular formula of $\mathrm{C}_{22} \mathrm{H}_{20} \mathrm{O}_{7}$ was determined by HRESIMS ( $m / z$ 397.1288 [M+H] $]^{+}$, calcd for $\left.\mathrm{C}_{22} \mathrm{H}_{21} \mathrm{O}_{7}: 397.1287\right)$, indicating $13^{\circ}$ of unsaturation. The IR absorption implied the presence of hydroxyls, $\alpha, \beta$-unsaturated ketone and aromatic ring at 3432,1674, 1656, 1593, and $1471 \mathrm{~cm}^{-1}$. Comparison of the NMR data with that of compound $\mathbf{1}$ suggested that $\mathbf{2}$ also had a spirobisnaphthalene skeleton. The difference between them mainly lay in the ${ }^{13} \mathrm{C}$ resonance at $\mathrm{C}-2^{\prime}, \mathrm{C}-3^{\prime}$, and $\mathrm{C}-4^{\prime}$ and an additional methoxy group at $\delta_{\mathrm{C}} 58.4 / \delta_{\mathrm{H}} 3.15(3 \mathrm{H}, \mathrm{s})$ in 2 . The HMBC correlation between $\delta_{\mathrm{H}} 3.15(3 \mathrm{H}, \mathrm{s})$ and $\delta_{\mathrm{C}} 80.5\left(\mathrm{C}-3^{\prime}\right)$ located the methoxy group at $\mathrm{C}-3^{\prime}$. Detailed analyses of ${ }^{1} \mathrm{H}-{ }^{1} \mathrm{H}$ COSY, HSQC and HMBC spectra accomplished the planar structure of 2 . The relative configuration of 2 was determined by ROESY experiment and comparison of its NMR data with that of 1. In the ROESY spectrum, $\mathrm{H}-3^{\prime}$ at $\delta_{\mathrm{H}} 4.15(1 \mathrm{H}, \mathrm{m})$ correlated with $\mathrm{H}-7$ at $\delta_{\mathrm{H}} 7.40(1 \mathrm{H}, \mathrm{d}, 8.0 \mathrm{~Hz})$. Similar CD cotton effects of 2 with that of 1 suggested that the absolute configurations of 2 were $3 S, 4 R, 3^{\prime} S, 4^{\prime} R$ (Fig. S9†).

Sarcosomycin C (3) was obtained as a yellow amorphous powder. The molecular formula was established as $\mathrm{C}_{21} \mathrm{H}_{18} \mathrm{O}_{7}$ by HRESIMS ( $m / z 383.1123[\mathrm{M}+\mathrm{H}]^{+}$, calcd for $\left.\mathrm{C}_{21} \mathrm{H}_{19} \mathrm{O}_{7}: 383.1131\right)$, indicating $13^{\circ}$ of unsaturation. The IR absorption implied the presence of hydroxyls, $\alpha, \beta$-unsaturated ketone and aromatic ring at 3424, 1669 (broad singlet), 1592, and $1468 \mathrm{~cm}^{-1}$. Comparison
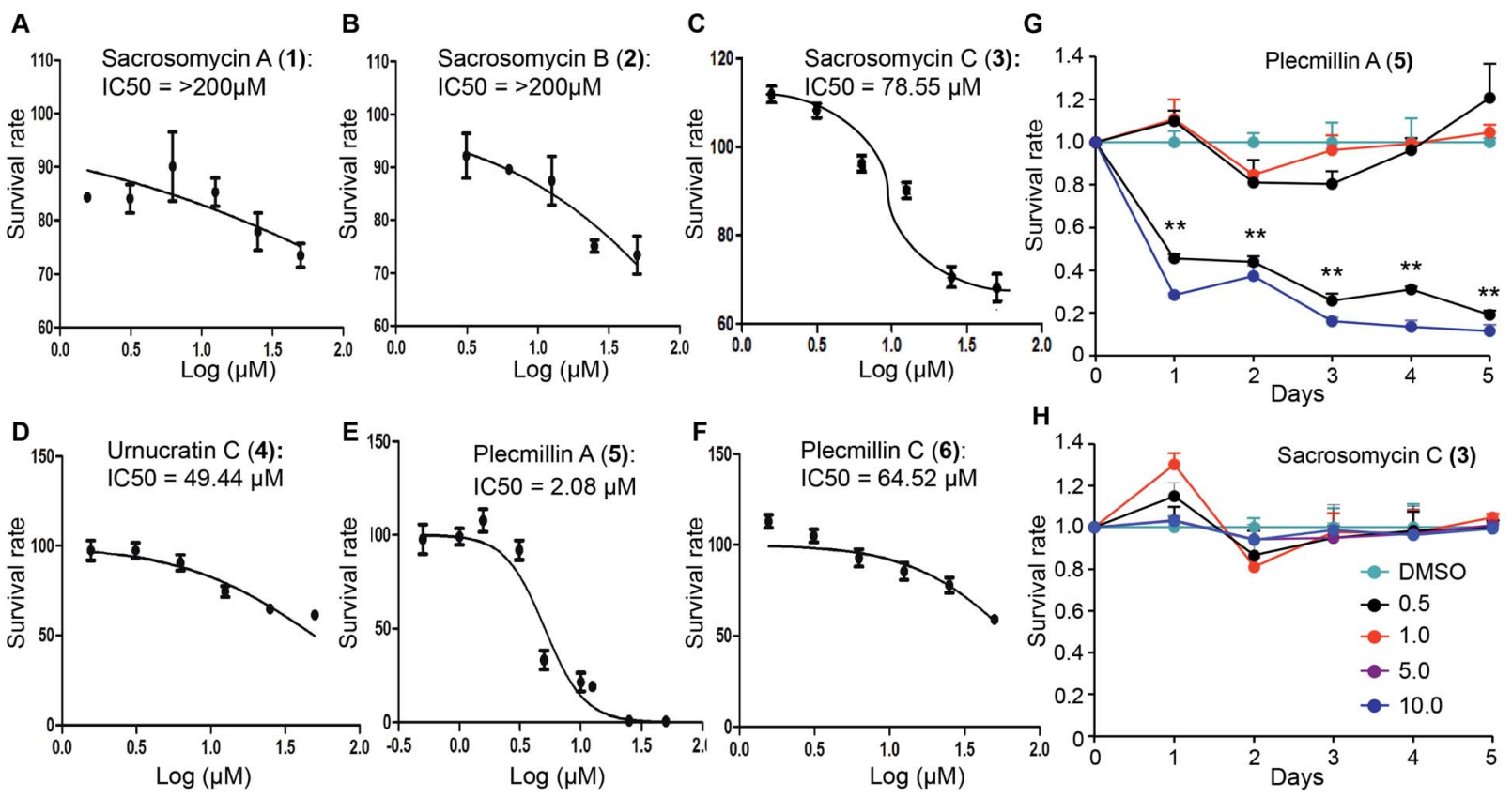

Fig. 4 Effects of compounds 1-6 on cell proliferation. (A-F) The IC 50 values of compounds 1-6 after 48 hour treatment of HCT116 cells were assessed by MTT assay. Sacrosomycin A-C (1-3) displayed greater than $200 \mu$ M of IC 50 . (G-H) Time- and dose-dependent growth of U2OS cells in the presence of Plecmillin A (5) or Sacrosomycin C (3). Data represent mean and standard deviation from three replicates. $* * P<0.0001$ compared with control groups at the corresponding time points. 
of the ${ }^{1} \mathrm{H}$ and ${ }^{13} \mathrm{C}$ NMR data with that of Plecmillin $\mathrm{E}$ indicated that they showed great similarity (Table 1). The main difference between them lay in the ${ }^{13} \mathrm{C}$ resonance of ${\mathrm{C}-2^{\prime}}^{\prime}$ and $\mathrm{C}-3^{\prime}$ and the absence of a methoxy group in 3, suggesting that compound 3 was a demethylated derivative of Plecmillin E. ${ }^{5}$ The ${ }^{1} \mathrm{H}-{ }^{1} \mathrm{H}$ COSY, HSQC and HMBC correlations confirmed the planar structure of 3 (Fig. 2). The relative configuration of 3 was determined based on 1D selective NOE correlations and by comparison of its NMR data with that of urnucratin C. In the 1D selective NOE experiment, irradiation of $\mathrm{H}-4\left(\delta_{\mathrm{H}} 5.24,1 \mathrm{H}, \mathrm{br} \mathrm{s}\right)$ enhanced $\mathrm{H}-6^{\prime}\left(\delta_{\mathrm{H}} 6.69,1 \mathrm{H}\right.$, dd, 7.8, $0.8 \mathrm{~Hz})$, while irradiation of $\mathrm{H}-3^{\prime}\left(\delta_{\mathrm{H}} 4.34,1 \mathrm{H}, \mathrm{dd}, 9.4,5.9\right.$ $\mathrm{Hz}$ ) enhanced $\mathrm{H}-7\left(\delta_{\mathrm{H}} 6.98,1 \mathrm{H}, \mathrm{d}, 8.4 \mathrm{~Hz}\right)$ (Fig. 3). Thus, the relative configurations of 3 were determined to be $1 S^{*}, 2 S^{*}, 3 R^{*}$, $4 R^{*}, 3^{\prime} S^{*}, 4^{\prime} R^{*}$. The CD cotton effects of 3 were consistent with that of Plecmillin E, ${ }^{5}$ indicating its absolute configurations to be $1 S, 2 S, 3 R, 4 R, 3^{\prime} S, 4^{\prime} R$ (Fig. S26 †). The biosynthetic origin of 1-6 also supported the deduction mentioned above. ${ }^{5,6}$

\section{Biological evaluation of spirobisnaphthalenes}

Spirobisnaphthalenes have shown anticancer activities. To this end, we evaluated the anticancer effect of these six compounds. We found that 48 hour treatment of human colorectal HCT116 cancer cells with Plecmillin A (5) demonstrated the strongest growth inhibitory effect with an $\mathrm{IC}_{50}$ of $\sim 2.1 \mu \mathrm{M}$, whereas the sacrosomycins were greater than $200 \mu \mathrm{M}$ (Fig. 4A-C). Subsequently, we monitored cell proliferation over five days in the presence of increasing concentrations of Plecmillin A (5) or one of the new spirobisnaphthalenes, sacrosomycin C (3). We found that Plecmillin A (5) significantly inhibited cell growth at and above $5 \mu \mathrm{M}$ (Fig. 4G). In contrast, sacrosomycin C (3) did not inhibit cell growth at least by $10 \mu \mathrm{M}$ (Fig. $4 \mathrm{H})$. These results are consistent with the $\mathrm{IC}_{50}$ data, suggesting a potential tumor suppressing role of Plecmillin A (5).

In our effort to determine how Plecmillin A (5) inhibited cancer cell growth, we measured the cell cycle profile by flow cytometry and found out that Plecmillin A (5) time-dependently induced accumulation of cells at the G2/M phase (Fig. 5A), suggesting that Plecmillin A (5) induces cell cycle arrest, which may contribute to the cancer cell growth inhibition. During analysis to understand the molecular mechanisms underlying the cell cycle arrest, we found that Plecmillin A (5), and to a much lesser degree, sacrosomycin C (3), increased the protein levels of P53 and P21 (Fig. 5B), indicating that this compound class upregulates the tumor suppressing P53-P21 pathway. On

A
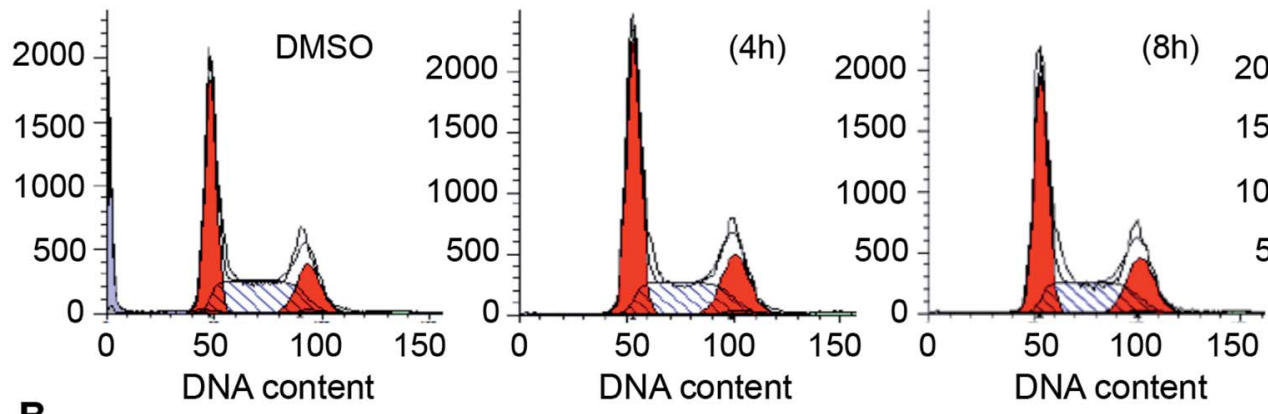

(12h)

B

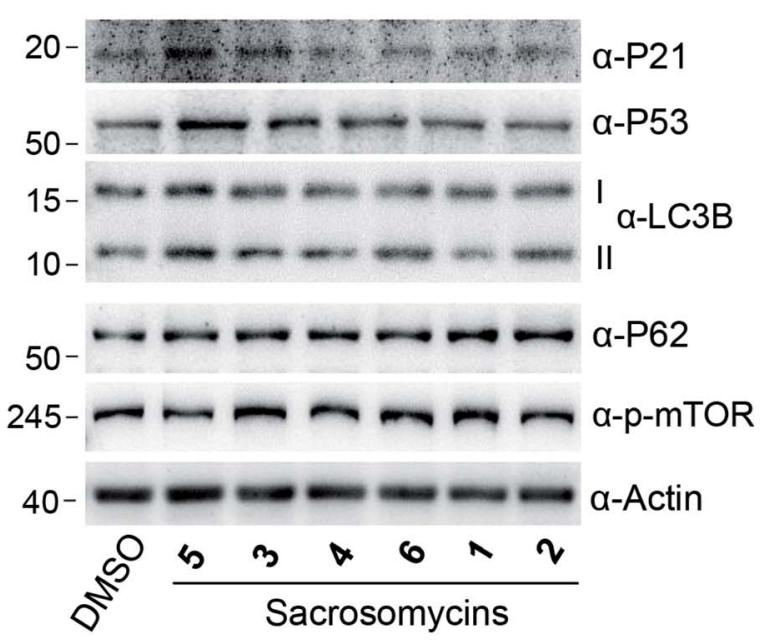

C

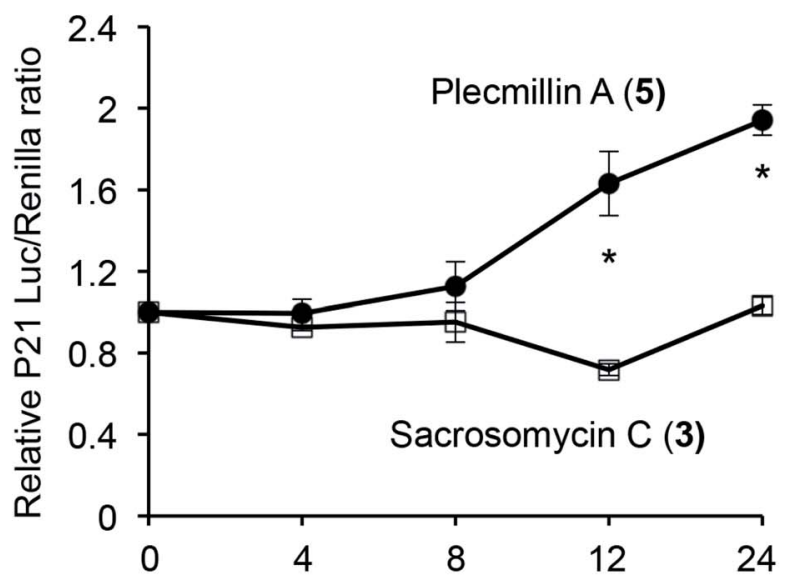

(h)

Fig. 5 Cell cycle arrest induced by Plecmillin A (5). (A) U2OS cells were treated with $5 \mu$ M Plecmillin A (5) for 0, 4, 8 and 12 hours and cell cycle profile was analyzed by flow cytometry. (B) U2OS cells were treated with $5 \mu M$ of compounds (1-6) for 6 hours, and protein expression was examined. I and II represent unlipidated and lipidated form of LC3B, respectively. (C) Luciferase reporter assay for P53-dependent transcription of CDKN1A. HEK293T cells were transfected with PGL3-P21 reporter and renilla luciferase vectors (1: 50 ) for 24 hours, treated with $5 \mu$ M Plecmillin A (5) or Sacrosomycin C (3) for indicated times. Data represent mean and standard of relative luciferase/renilla ratio from three independent experiments. 
the other hand, these compounds did not clearly affect the expression of LC3B or P62 (Fig. 5B), two markers for autophagy, indicating that they did not affect the autophagic pathway.

To confirm that these compounds indeed activated the P53P21 pathway, we constructed a luciferase reporter assay to measure P53-dependent transcriptional regulation of CDKN1A, the gene encoding P21. The results show that at the dose of 5 $\mu \mathrm{M}$, Plecmillin A (5), but not sacrosomycin C (3), timedependently increased the transcription level of CDKN1A (Fig. 5C). Since P21 inhibits the cyclin-dependent kinase to induce cell cycle arrest in G1 or G2/M phase, ${ }^{16,22-24}$ these results are consistent with the G2/M arrest by Plecmillin A (5).

To determine how spirobisnaphthalenes regulate the P53P21 pathway and cell survival, we conducted a dose-dependent study of Plecmillin A (5) and sacrosomycin C (3). The results show that Plecmillin A (5), but not sacrosomycin C (3), greatly increased the protein level of P53 and P21 (Fig. 6A). There was a moderate increase in the MEK/ERK pathway as evidenced by a small increase in the levels of phosphorylated MEK and ERK (Fig. 6A); however, this increase in this pathway may have not effect the cell survival. Consistently, we observed a gradual increase in the level of cleaved poly (ADP-ribose) polymerase (PARP), a known cell death marker, ${ }^{25-27}$ by Plecmillin A (5), and to a much lesser degree sacrosomycin C (3) (Fig. 6A). Further, Plecmillin A (5), but not sacrosomycin C (3), dose-dependently reduced the long-term survival capability of U2OS cancer cells
(Fig. 6B-C). These results suggest cell death induction by higher doses of spirobisnaphthalenes.

Further, we found that Plecmillin A (5) time-dependently increased the protein levels of P53 and P21 (Fig. 7A). We noticed a weak induction of PARP cleavage (Fig. 7A), likely due to shorter incubation time than in previous experimental settings. To further confirm the induction of the P53-P21 pathway, we performed quantitative PCR (qPCR) to measure the mRNA levels of TP53 and CDKN1A. Our results show that Plecmillin A (5) induced upregulation of both genes during the first $8 \mathrm{~h}$ of treatment but then slightly declined at $24 \mathrm{~h}$ of treatment (Fig. 7B). The reduction at $24 \mathrm{~h}$ might be due to cell death after prolonged compound treatment. Similar to shortterm growth curve results, Plecmillin A (5) time-dependently inhibited the long-term cell survival (Fig. 7C). To determine if this compound directly induces cell death, we measured dead cell population using trypan blue exclusion assay. The results show that Plecmillin A (5) time-dependently induced cell death (Fig. 7D). To understand if this compound could non-selectively kill normal cells, we measured cell death of a normal hepatocyte LO2 after treatment with Plecmillin A or Sacrosomycin C. The results show almost no cell death induction by these two compounds (Fig. 7E), indicating a relatively selective cell death induction in cancer cells by these compounds. Although the magnitude of cell death seemed to be weak, the increase was significant, supporting a chronic tumor suppressing role of this class of compound.

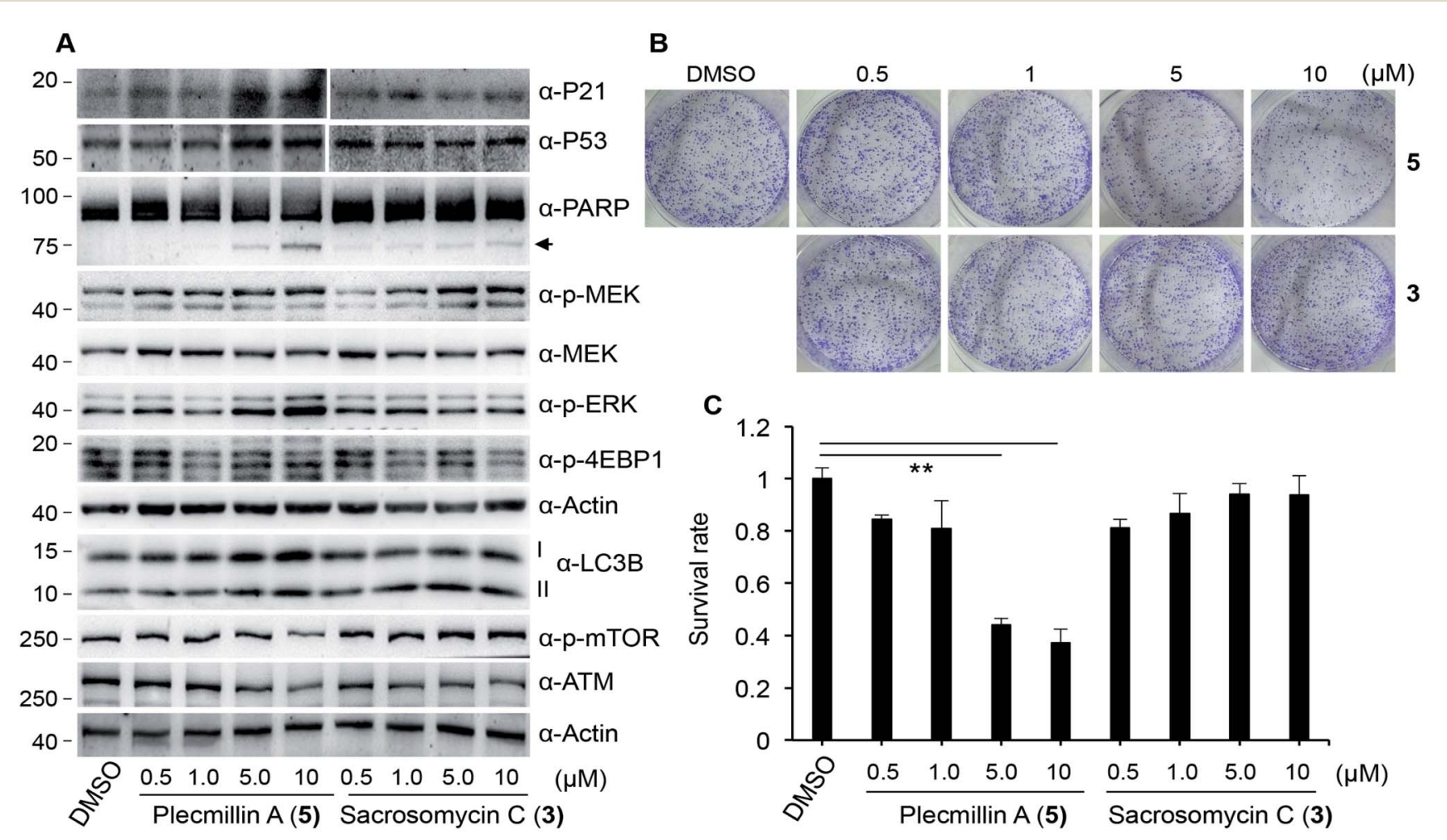

Fig. 6 Dose-dependent P53-P21 induction and cell growth inhibition by Plecmillin A (5). (A) U2OS cells were treated with increasing doses of Plecmillin A (5) or Sacrosomycin C (3) for 12 hours and protein expression was assessed. Arrow indicates cleaved PARP. (B) Representative images of clonogenic survival of cells from A. (C) Quantitation of B. Data represent mean and standard deviation from three replicates. $* * P<0.0001$ compared with control group. 


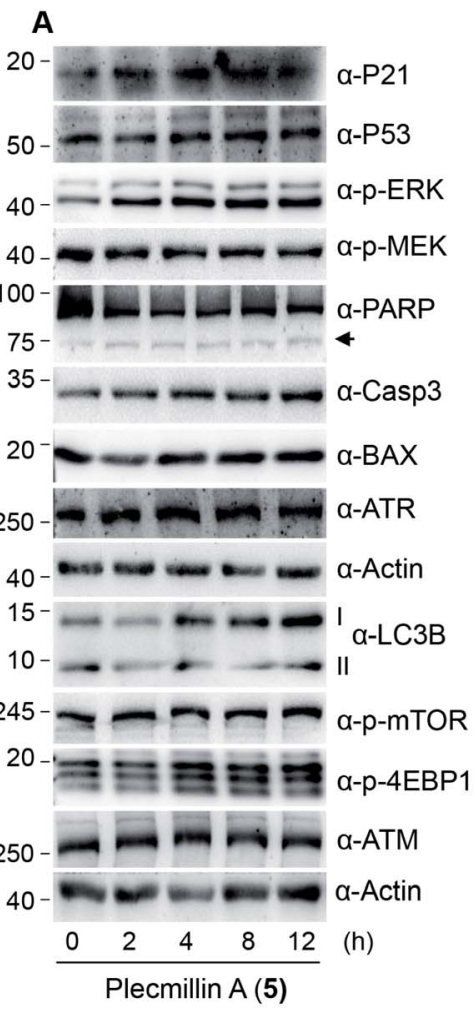

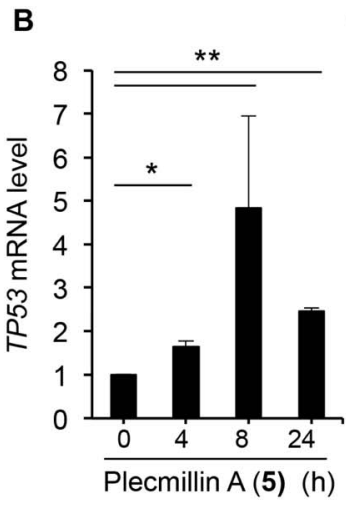

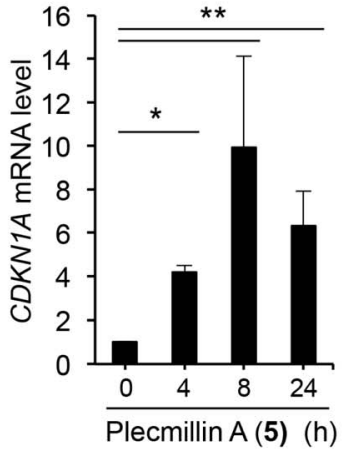

C

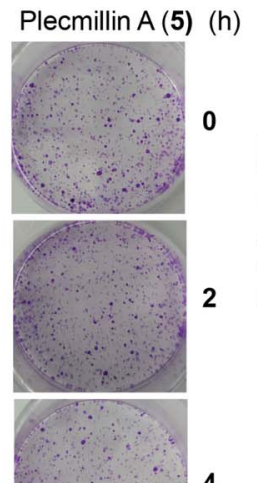

D

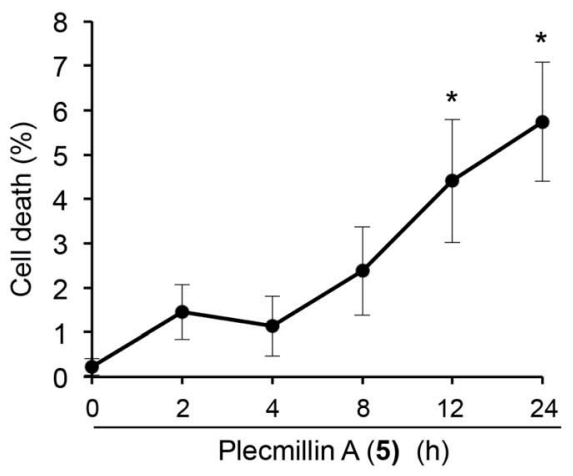

E

12

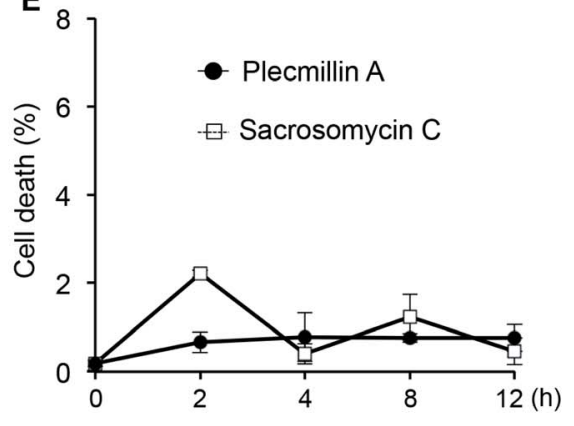

Fig. 7 Time-dependent P53-P21 induction and cell growth inhibition by Plecmillin A (5). (A) U2OS cells were treated with $5 \mu M$ of Plecmillin A (5) for $0,2,4,8$ and 12 hours and protein expression was assessed. Arrow indicates cleaved PARP. (B) qPCR results of TP53 and CDKN1A in U2OS cells treated with $5 \mu \mathrm{M}$ of Plecmillin A (5) for 0, 4, 8 and 24 hours. (C) Representative images of clonogenic survival of cells from A. (D) Quantitation of C. (E) LO2 cells were treated with $10 \mu \mathrm{M}$ of Plecmillin A (5) or Sacrosomycin C for 0, 4, 8 and 12 hours, and cell death was assessed. Data represent mean and standard deviation from three replicates. $* P<0.01$ and $* * P<0.0001$ compared with the control group.

\section{Conclusion}

In summary, three new and three known spirobisnaphthalenes were obtained from the extract of a cultured nonsporulating endolichenic fungus. The three novel compounds were described as two partially saturated naphthalene rings joined together by one oxygen bridge $\left(\mathrm{C} 4^{\prime}-\mathrm{C} 4\right)$ and one carbon-carbon bridge (C4'-C6), which was belonged to the fourth subtype of spirobisnaphthalenes. This is also the first report of spirobisnaphthalenes obtained from endolichenic fungus and from this family Sarcosomataceae. Anticancer activity evaluation reveals that Plecmillin A (5) displayed potent growth inhibitory effect on colon HCT116 and osteosarcoma U2OS cancer cell lines, but not on normal hepatocytes. Mechanically, Plecmillin A (5) induced the upregulation of the P53-P21 pathway, correlating with the cell cycle arrest effect by this compound. Plecmillin A (5) treatment at relatively higher doses induced cancer cell death. These biological results allow us to identify more potent spirobisnaphthalenes, for instance through chemical modification of the three novel compounds, in the anticancer regimen in the near future. In conclusion, spirobisnaphthalenes isolated from an endolichenic fungus strain (CGMCC 3.15192) demonstrated potential anticancer effect.

\section{Experimental procedure}

General experimental procedures. Optical rotations were measured on a JASCO P-1020 digital spectropolarimeter. IR spectra were obtained using a JASCO FT/IR-480 plus spectrometer. ESI-MS spectra were recorded on a Finigan LCQ Advantage MAX mass spectrometer. HRESIMS spectra were recorded using a Micromass Q-TOF and an Agilent $6210 \mathrm{LC} /$ MSD TOF mass spectrometer. 1D and 2D NMR spectra were recorded using a Bruker Avance $400 \mathrm{MHz}$ NMR spectrometer. Column chromatography was performed using silica gel (200300 mesh, Qingdao) and ODS (60-80 $\mu \mathrm{m}, \mathrm{YMC})$. TLC was performed on pre-coated silica gel plates (silica gel GF254, $1 \mathrm{~mm}$ ). Semipreparative HPLC was performed on a SHIMADZU LC-6AD Liquid Chromatography with SPD-20A Detector, using an ODS column [Welch Materials XB-C18 column $(4.6 \times 250 \mathrm{~mm}, 5$ $\mu \mathrm{m})$, YMC-Pack ODS-A $(10.0 \times 250 \mathrm{~mm}, 5 \mu \mathrm{m})]$. All culture media and glassware were autoclaved prior to use. The slate cultivation was carried out in an EYELA LTI-700 incubator. The seed cultures were grown in an HZQ-Q constant temperature breeding shaker.

Fungal material. The nonsporulating endolichenic fungus strain CGMCC 3.15192 was isolated from lichen Peltigera elisabethae var. mauritzii (Gyeln.) J. C. Wei collected in the Changbai Mountain in Jilin Province of China. The fungus was 
identified as a member of Sarcosomataceae according to its molecular identification by Professor Liang-Dong Guo in the Institute of Microbiology, Chinese Academy of Sciences, Beijing.

Fermentation. The fungus was cultured on slants of potato dextrose agar at $25{ }^{\circ} \mathrm{C}$ for 4 days. Agar plugs were used to inoculate Erlenmeyer flasks $(250 \mathrm{~mL})$, each containing $50 \mathrm{~mL}$ of media $(0.4 \%$ glucose, $1 \%$ malt extract, and $0.4 \%$ yeast extract), and the final $\mathrm{pH}$ of the media was adjusted to 6.5 before sterilization. Flask cultures were incubated at $25{ }^{\circ} \mathrm{C}$ on a rotary shaker at $220 \mathrm{rpm}$ for 3-4 days. Fermentation was carried out in thirty Erlenmeyer flasks $(500 \mathrm{~mL})$, each containing $70 \mathrm{~g}$ of rice. Distilled $\mathrm{H}_{2} \mathrm{O}(105 \mathrm{~mL})$ was added to each flask, and the contents were soaked overnight before autoclaving at $15 \mathrm{lb}$ per $\mathrm{in}^{2}$ for $30 \mathrm{~min}$. After cooling to room temperature, each flask was inoculated with $5.0 \mathrm{~mL}$ of the inoculum and incubated at $25{ }^{\circ} \mathrm{C}$ for 47 days.

Extraction and isolation. The fermented material was extracted repeatedly with EtOAc $(0.5 \mathrm{~L} \times 30 \times 4)$, and the organic solvent was evaporated to dryness under vacuum to afford the crude extract (32.2 g), which was fractionated by silica gel column chromatography eluted with petroleum ether and $\mathrm{MeOH}$ successively. The $\mathrm{MeOH}$ portion was separated by ODS column chromatography using $\mathrm{MeOH}-\mathrm{H}_{2} \mathrm{O}$ gradient elution to obtain five fractions (W1-W5). Fractions W2 $50 \% \mathrm{MeOH}$ in $\left.\mathrm{H}_{2} \mathrm{O}, \mathrm{v} / \mathrm{v}\right)$ and $\mathrm{W} 3\left(70 \% \mathrm{MeOH}\right.$ in $\left.\mathrm{H}_{2} \mathrm{O}, \mathrm{v} / \mathrm{v}\right)$ showed different degrees of cytotoxic activities against five cancer cell lines (HL60, SMMC-7721, A-549, MCF-7 and SW480). The fraction W2 (1.76 g) was chromatographed on a Sephadex LH-20 column eluting with $\mathrm{CHCl}_{3}-\mathrm{MeOH} 1$ : 1 to yield four subfractions (W2a to W2-d). W2-b (1.15 g) was subjected to a silica gel column chromatography eluted with a stepwise elution of $\mathrm{CHCl}_{3}$ / acetone (from $98: 2$ to $0: 100$ ) to obtained 14 subfractions. W2b-h (183 mg) was purified by RPHPLC (40\% MeOH in $\left.\mathrm{H}_{2} \mathrm{O}, \mathrm{v} / \mathrm{v}\right)$ on an YMC-Pack ODS-A column $(10.0 \times 250 \mathrm{~mm}, 5 \mu \mathrm{m}, 4.0$ $\left.\mathrm{mL} \mathrm{min}^{-1}\right)$ to yield compounds $4\left(14.5 \mathrm{mg}, t_{\mathrm{R}}=23.3 \mathrm{~min}\right)$ and 6 $\left(6.9 \mathrm{mg}, t_{\mathrm{R}}=24.1 \mathrm{~min}\right)$. Compound $1\left(8.2 \mathrm{mg}, t_{\mathrm{R}}=25.3 \mathrm{~min}\right)$ was afforded from the subfraction W2-b-g (52.5 mg) using RPHPLC (40\% MeOH in $\left.\mathrm{H}_{2} \mathrm{O}, \mathrm{v} / \mathrm{v}\right)$. Compound $2\left(18.5 \mathrm{mg}, t_{\mathrm{R}}=\right.$ $16.3 \mathrm{~min}$ ) was afforded from the subfraction $\mathrm{W} 2-\mathrm{b}-\mathrm{i}(52.5 \mathrm{mg})$ using RPHPLC (25\% $\mathrm{CH}_{3} \mathrm{CN}$ in $\left.\mathrm{H}_{2} \mathrm{O}, \mathrm{v} / \mathrm{v}\right)$. Compound 3 (2.5 mg, $\left.t_{\mathrm{R}}=15.8 \mathrm{~min}\right)$ was afforded from the subfraction W2-b-72 (50.0 $\mathrm{mg})$ using RPHPLC $\left(20 \% \mathrm{CH}_{3} \mathrm{CN}\right.$ in $\mathrm{H}_{2} \mathrm{O}$, v/v). Meanwhile, the fraction W3 (1.49 g) was chromatographed on a Sephadex LH-20 column chromatography eluted with $\mathrm{CHCl}_{3}-\mathrm{MeOH} 1: 1$ to yield five subfractions (W3-a to W3-e). W3-c (0.43 g) was subjected to a silica gel column chromatography eluted with a stepwise elution of $\mathrm{CHCl}_{3}$ /acetone (from $98: 2$ to $0: 100$ ) to obtained five subfractions. W3-c-2 $(50.4 \mathrm{mg})$ was purified by RPHPLC $(40 \%$ $\mathrm{MeOH}$ in $\mathrm{H}_{2} \mathrm{O}$, v/v) on an YMC-Pack ODS-A column $(10.0 \times 250$ $\left.\mathrm{mm}, 5 \mu \mathrm{m}, 4.0 \mathrm{~mL} \mathrm{~min}^{-1}\right)$ to yield compound $5\left(7.2 \mathrm{mg}, t_{\mathrm{R}}=\right.$ $15.7 \mathrm{~min})$.

Sarcosomycin A (1): yellow powder; $[\alpha]_{\mathrm{D}}^{25} 26.8(c=0.10$, $\mathrm{MeOH}) ; \mathrm{UV}(\mathrm{MeOH}): \lambda_{\max }(\log \varepsilon)=216 \mathrm{~nm}$ (4.41), $255 \mathrm{~nm}$ (3.98), $319 \mathrm{~nm}$ (3.56); CD (MeOH) $214(\Delta \varepsilon-10.6), 227(\Delta \varepsilon+5.7), 260(\Delta \varepsilon$ +10.9), $312(\Delta \varepsilon-1.4) \mathrm{nm}$; IR (KBr): $\nu_{\max }=3423,2925,2854$,
1657, $1594 \mathrm{~cm}^{-1}$; HR-ESI-MS: $\left(\mathrm{m} / z 383.1116[\mathrm{M}+\mathrm{H}]^{+}\right.$, calcd for $\mathrm{C}_{21} \mathrm{H}_{19} \mathrm{O}_{7}$ : 383.1131). ${ }^{1} \mathrm{H}$ and ${ }^{13} \mathrm{C}-\mathrm{NMR}$ data see Table 1.

Sarcosomycin B (2): yellow powder; $[\alpha]_{\mathrm{D}}^{25} 3.7(c=0.95$, $\mathrm{MeOH}) ; \mathrm{UV}(\mathrm{MeOH}): \lambda_{\max }(\log \varepsilon)=218 \mathrm{~nm}$ (4.34), $254 \mathrm{~nm}$ (3.90), $323 \mathrm{~nm}$ (3.48); UV ( $\left.\mathrm{CH}_{3} \mathrm{CN}\right): \lambda_{\max }(\log \varepsilon)=218 \mathrm{~nm}(4.34), 254 \mathrm{~nm}$ (3.90), $323 \mathrm{~nm}$ (3.48); CD (MeOH): $214(\Delta \varepsilon-11.5), 260(\Delta \varepsilon+9.7)$, $320(\Delta \varepsilon-1.9) \mathrm{nm} ; \mathrm{CD}\left(\mathrm{CH}_{3} \mathrm{CN}\right): 214(\Delta \varepsilon-6.3), 227(\Delta \varepsilon+6.7), 260$ $(\Delta \varepsilon+11.6), 315(\Delta \varepsilon-1.7) \mathrm{nm}$; IR (KBr): $\nu_{\max }=3433,1674,1656$, $1593 \mathrm{~cm}^{-1}$; HR-ESI-MS: $\left(\mathrm{m} / z\right.$ 397.1288 $[\mathrm{M}+\mathrm{H}]^{+}$, calcd. for $\mathrm{C}_{22} \mathrm{H}_{21} \mathrm{O}_{7}$ : 397.1287). ${ }^{1} \mathrm{H}$ and ${ }^{13} \mathrm{C}-\mathrm{NMR}$ data see Table 1.

Sarcosomycin C (3): yellow powder; $[\alpha] 5.2(c=0.11, \mathrm{MeOH})$; UV (MeOH): $\lambda_{\max }(\log \varepsilon)=202 \mathrm{~nm}(-4.68), 254 \mathrm{~nm}$ (3.98), $317 \mathrm{~nm}$ (3.65); IR (KBr): $\nu_{\max }=3423,2924,2854,1669,1591$, 1281, $1241 \mathrm{~cm}^{-1}$; HR-ESI-MS: $\left(\mathrm{m} / z 383.1123[\mathrm{M}+\mathrm{H}]^{+}\right.$, calcd for $\mathrm{C}_{21} \mathrm{H}_{19} \mathrm{O}_{7}$ : 383.1131). ${ }^{1} \mathrm{H}$ and ${ }^{13} \mathrm{C}-\mathrm{NMR}$ data see Table 1.

\section{Biological materials and methods}

Cell cultures. Human cancer cell lines were obtained from American Type Culture Collection (ATCC). The cell lines were cultured in Dulbecco's modified eagle medium (DMEM) (for U2OS and HEK293T) or PRMI1640 medium (for HCT116) supplemented with $10 \%$ fetal bovine serum (FBS, \#FSP500, ExCellBio), $100 \mathrm{U} \mathrm{mL}^{-1}$ penicillin and $100 \mu \mathrm{gL}^{-1}$ streptomycin (\#15140-122, Gibco) in 5\% $\mathrm{CO}_{2}$ and $37{ }^{\circ} \mathrm{C}$ incubator. The cells were passaged once every 3-4 days, and cells in the logarithmic phase were used for the experiment.

Measurement of cell viability. Cell viability was measured by MTT assay. For $\mathrm{IC}_{50}$ determination, HCT116 cells were plated at the density of $5 \times 10^{4} / \mathrm{mL}$ in 96 well plate overnight, treated with varying concentrations of compounds for $48 \mathrm{~h}$, add $20 \mu \mathrm{L}$ MTT (\#T100896, Aladdin) into each well and cultured for $3 \mathrm{~h}$, discarded the supernatant, added $150 \mu \mathrm{L}$ DMSO to each well, and measured the OD value at $570 \mathrm{~nm}$. For measuring cell growth, U2OS cells were seeded at the density of $5 \times 10^{4} / \mathrm{mL}$ in 96 well plates for 1-5 days, and MTT assay was performed as above. The Graphpad Prism5 was used to calculate the $\mathrm{IC}_{50}$ value.

Western blotting. For the detection of protein expression, 5 $\times 10^{5}$ cells were plated at 6 well plates overnight, treated with compounds for $6 \mathrm{~h}$ or indicated times. The cells were harvested and lysed in $50 \mu \mathrm{L}$ lysis buffer (\#P0013, Beyotime) on ice for $30 \mathrm{~min}$, sonicated and centrifuged to collect the supernatant. The protein concentration in the supernatant was quantitated by BCA protein assay kit (\#23225, Pierce) and equal amount of total proteins from each sample was loaded onto SDS-PAGE followed by detection using specific antibodies. Antibodies used include the anti-P53 (\#GTX70214, GeneTex), anti-P21 (\#sc6246, Santa Cruz Biotechnologies), $\beta$-actin (AP0060, Bioworld), anti-GADD45a (\#ab180768, abcam), anti-Apaf-1 (\#ab2000, abcam), anti-MDM2 (\#ab38618, abcam), anti-14-3-3 $\sigma$ (\#GTX100801, GeneTex), anti-PUMA (\#GTX109675, GeneTex), anti-LC3B (NB100-2220, Novus Biologicals), anti-P62 (\#NBP142821, Novus biologicals), anti-phospho-Chk1 (Ser345, CST), anti-ATR (\#GTX70109, GeneTex), anti-ATM (\#GTX70103, GeneTex), anti-PARP (\#9542, CST), anti-Phospho-MEK1/2 (Ser217/ 221, CST), anti-MEK (\#9122, CST), anti-P44/42 MAPK (Erk112) 
(\#9102, CST), anti-Bax (\#2772, CST), anti-phospho-mTOR (Ser2448, CST), anti-Caspase3 (\#9662, CST), anti-P-4EBP1 (Ser65, CST). All primary antibodies were diluted in TBST buffer. The relative expression levels of P53 and P21 proteins were quantitated by measuring the band intensity using the NIH Image J software.

Real-time PCR. Total RNA was extracted followed by the RNeasy plus mini kit 50 (\#74134, Qiagene). The cDNA is synthesized using the Revert Aid first strand cDNA synthesis kit according to the manufacturer's procedure (\#K1622, Thermo Fisher). Real-time PCR was performed on a CFX96 Real-Time PCR system (Bio-Rad, Hercules, CA) with SYBR Green (Invitrogen, \#208054). Primers for RT-PCR are: TP53-F: $5^{\prime}$ CTTCCATTTGCTTTGTCCCG-3', TP53-R: 5'-CATCTCCCAAACATCCCTCAC-3', CDKN1A (P21)-F: 5'-AACTAGGCGGTTGAATGAGAG-3', CDKN1A (P21)-R: 5'-GAGGAAGTAGCTGGCATGAAG3', HPRT1-F: 5'-AGCTTGCTGGTGAAAAGGA-3', HPRT1-R: 5' CCAAACTCAACTTGAACTCTCATC- $3^{\prime}$.

Luciferase reporter assay. To analyze P53-dependent transcriptional regulation of CDKN1A expression, we carried out luciferase reporter assay. Briefly, 8 copies of the P53-binding site of the CDKN1A's promoter sequence were inserted into the PGL3-Basic plasmid. HEK293T cell were transfected with the P21 luciferase reporter plasmid together with a renilla control vector by Lipo2000 (\#11668019, ThermoFisher). After $24 \mathrm{~h}$, the cells were treated with $5 \mu \mathrm{M}$ compounds for $0,4,8,12$ and $24 \mathrm{~h}$. Luciferase activities were measured followed the DualLuciferase ${ }^{\circ}$ Reporter Assay System Kit (\#E1910, Promega).

Cell cycle assay. U2OS cell were treated with $5 \mu \mathrm{M}$ Plecmillin A for $0,4,8$ and 12 hours, harvested, washed once with PBS, fixed in $70 \%$ ethanol, stained with PI in the presence of RNase A (\#C1052, Beyotime), analyzed by flow cytometry. The data were analyzed using the ModFitLT software.

Clonogenic survival assay. U2OS cells were treated with different concentrations of Plecmillin A for 12 or varying hours, trypsinized into single cell suspension, replated at the density of 500 cells per well into 6 well plates and incubated for 10 days. Colonies were stained with $0.1 \%$ crystal violet, washed under tap water, air-dried and images were taken. Quantitation of cell survival was performed either by quantitating the image intensity or dissolving the plates by $1 \%$ SDS and measuring the absorption at $570 \mathrm{~nm}$. All of the experimental groups were repeated three times.

\section{Conflicts of interest}

There are no conflicts to declare.

\section{Acknowledgements}

This work was supported by grants from National Key Research and Development Program of China (Grant Number: 2018YFC0311002).

\section{Notes and references}

1 B. Helge and Z. Axel, Phytochemistry, 2000, 55, 311-316.
2 B. Bjorn, W. Barbara and Z. Axel, J. Antibiot., 2000, 53, 153157.

3 H. Ogishi, N. Chiba, T. Mikawa, T. Sasaki, S. Miyaji, and M. Sezaki, Jpn Pat., JP 01294686 A, 1989.

4 L. Zhou, J. Zhao, T. Shan, X. Cai and Y. Peng, Mini-Rev. Med. Chem., 2010, 10, 977-989.

5 K. Wang, L. Bao, K. Ma, W. Qi, F. Song, Y. Yao, W. Yin, L. Zhang, Y. Huang, J. Han and H. Liu, Eur. J. Org. Chem., 2016, 25, 4338-4346.

6 X. Liu, R. William, J. Thomas, R. Marc, M. Liu, P. Huang, Z. Liu, Y. Wang, C. Nicholas, S. Cassandra, H. Scott, M. Aaron and L. Zhang, J. Nat. Prod., 2012, 75, 15341538.

7 X. Liu, Y. Zhao, W. Wang, M. Wang and L. Zhou, Youji Huaxue, 2017, 37, 2883-2894.

8 C. P. Laptenko, Cell Death Differ., 2006, 13, 951-961.

9 S. Lowe, E. Schmitt, S. Smith, B. Osborne and T. Jacks, Nature, 1993, 362, 847-849.

10 E. Yonish-Rouach, D. Resnitzky, J. Lotem, L. Sachs, A. Kimchi and M. Oren, Nature, 1991, 352, 345-347.

11 A. Clarke, C. Purdie, D. Harrison, R. Morris, C. Bird, M. Hooper and A. Wyllie, Nature, 1993, 362, 849-852.

12 T. Miyashita, S. Krajewski, M. Krajewska, H. Wang, H. Lin, D. Liebermann, B. Hoffman and J. Reed, Oncogene, 1994, 9, 1799-1805.

13 W. Deiry, T. Tokino, V. Velculescu, D. Levy, R. Parsons, J. Trent, D. Lin, W. Mercer, K. Kinzler and B. Vogelstein, Cell, 1993, 75, 817-825.

14 J. Harper, G. Adami, N. Wei, K. Keyomarsi and S. Elledge, Cell, 1993, 75, 805-816.

15 W. Hoffman, S. Biade, J. Zilfou, J. Chen and M. Murphy, J. Biol. Chem., 2002, 277, 3247-3257.

16 E. Kastenhuber and S. Lowe, Cell, 2017, 170, 1062-1078.

17 C. Deng, P. Zhang, J. Harper, S. Elledge and P. Leder, Cell, 1995, 82, 675-684.

18 J. Brugarolas, C. Chandrasekaran, J. Gordon, D. Beach, T. Jacks and G. Hannon, Nature, 1995, 377, 552-557.

19 L. Donehower, M. Harvey, B. Slagle, M. McArthur, C. Montgomery, J. Butel and A. Bradley, Nature, 1992, 356, 215-221.

20 K. Lohr, C. Moritz, A. Contente and M. Dobbelstein, J. Biol. Chem., 2003, 278, 32507-32516.

21 I. Shats, M. Milyavsky, X. Tang, P. Stambolsky, N. Erez, R. Brosh, I. Kogan, I. Braunstein, M. Tzukerman, D. Ginsberg and V. Rotter, J. Biol. Chem., 2004, 279, 5097650985.

22 Y. Xiong, G. Hannon, H. Zhang, D. Casso, R. Kobayashi and D. Beach, Nature, 1993, 366, 701-704.

23 T. Abbas and A. Dutta, Nat. Rev. Cancer, 2009, 9, 400-414. 24 A. Karimian, Y. Ahmadi and B. Yousefi, DNA Repair, 2016, 42, 63-71.

25 P. Duriez and G. Shah, Biochem. Cell Biol., 1997, 75, 337-349. 26 F. Alnemri, G. Litwack and E. Alnemri, J. Biol. Chem., 1994, 269, 30761-30764.

27 D. Nicholson, A. Ali, N. Thornberry, J. Vaillancourt, C. Ding, M. Gallant, Y. Gareau, P. Griffin, M. Labelle and Y. Lazebnik, Nature, 1995, 376, 37-43. 